\title{
Use of virtual simulations for improving knowledge transfer among baccalaureate nursing students
}

\author{
Dana Tschannen, Michelle Aebersold, Elizabeth McLaughlin, J essica Bowen, J on Fairchild \\ School of Nursing, University of Michigan, Michigan, United States
}

Correspondence: Dana Tschannen. Address: Division of Nursing Business and Health Systems, 400 North Ingalls, Ann Arbor, Michigan 48109-5482. Telephone: 734-764-8152. Fax: 734-647-2416. Email: djvs@umich.edu.

Received: December 20, 2011

Accepted: January 29, $2012 \quad$ Published: August 1, 2012

DOI : $10.5430 /$ jnep.v2n3p15

URL: http://dx.doi.org/10.5430/jnep.v2n3p15

\begin{abstract}
Background: Use of simulation has been identified as an integrative strategy to bridge theory to practice and has been identified as a need in educating nurses in the future. Use of simulation provides an opportunity for nursing students to deliberately practice skills needed to be an expert nurse. The purpose of this study was to explore the use of virtual simulations to improve knowledge transfer of nursing students in one Midwest University.

Methods: This study used a quasi-experimental design with 115 nursing students in one University. All students received education on topics related to conflict management, priority-setting, and patient safety. The intervention group also participated in three virtual simulations. To evaluate knowledge transfer, performance on an individual simulation was evaluated using the Capacity to Rescue Instrument (CRI). Comparisons were made among the two groups using ANOVA.

Results: Total CRI score for the intervention group ( $m=21.98$, SD 4.29) was significantly higher than the score for the control group $(\mathrm{m}=20.09$, SD 4.05). Therefore, students participating in virtual simulations were able to transfer the knowledge learned in the classroom better than those not participating in the virtual simulations.

Conclusions: Efforts for providing more opportunities for deliberate practice of critical skills (e.g. communication, conflict management, priority setting) must be provided. The addition of virtual simulations focused on the deliberate practice of specified skills improved the students' performance. Use of a virtual environment may provide greater access to practice opportunities at a much lower cost than high fidelity simulators.
\end{abstract}

\section{Key words}

Simulation, Nursing, Virtual worlds, Second life, Knowledge transfer

\section{I ntroduction}

Nurses play an essential role in patient safety, as many nurses provide bedside patient monitoring in the acute care setting. Nurses perform this monitoring while managing multiple complex technologies where the margin of error is small. Additionally, nurses engage in communication activities with multiple health care practitioners and must be effective team members; this includes being an effective leader and follower, depending on the situation ${ }^{[1,2]}$. Enabling nurses to function well is dependent upon two key areas: 1) appropriate education and training, and 2) the ability to transfer the skill set learned in the classroom into the actual patient care environment. Knowledge transfer is defined as the ability to access and 
utilize intellectual resources that one has learned in a situation where those resources are relevant ${ }^{[3]}$. Transfer of knowledge and psychomotor skills from classroom to bedside is an important function in nursing.

Ericsson's theory on the acquisition of expert practice supports the development of nursing skills and the transfer of knowledge ${ }^{[4]}$. This framework posits that to acquire expert performance one must engage in deliberate practice activities focused on improving an aspect of performance (e.g. technical skills, communication skills, priority setting). Although students can improve skills with experience and often do, it is the engagement in the deliberate practice of skills that allow them to progress beyond initial proficiency to expertise in practice. Deliberate practice involves highly structured practice activities, like simulations, that allow students to reflect immediately upon their performance and receive detailed feedback they can incorporate into future actions. Use of simulation as an integrative strategy to bridge theory to practice has been identified as a need in educating nurses in the future ${ }^{[5]}$. For this reason, the purpose of this study was to determine the impact of virtual reality simulations on knowledge transfer among nursing students.

\section{Literature review}

Both medicine and nursing use simulation in both education and training programs in an effort to provide opportunities for practice in a safe environment. Simulation has been shown to increase patient safety, improve clinical judgment and can be used to teach/evaluate specific clinical skills ${ }^{[6]}$. A significant benefit of using simulation includes its ability to mimic real life situations without putting patients at risk ${ }^{[7-8]}$. The benefits of simulation in medical education are well established in the literature ${ }^{[9-12]}$. In nursing, a systematic review on the effectiveness of simulation showed that simulation increased the nursing student's clinical skills in a majority of the studies reviewed as opposed to other training methods (e.g. standardized patients, skills lab) ${ }^{[13]}$.

Simulation can help students develop the ability to apply previously learned knowledge in novel situations (knowledge transfer) when compared to other forms of education ${ }^{[14]}$. A study on advanced life support training using a high-fidelity mannequin showed physicians who participated in simulations designed to teach them how to be an effective leader in a cardiac arrest performed better during actual cardiac arrests ${ }^{[15]}$. Simulation also provides opportunities for students and nurses to engage in deliberate practice using evidence-based guidelines ${ }^{[16]}$. In addition, simulation has shown to improve student's level of confidence ${ }^{[17-18]}$.

Although evidence has proven utilizing the high fidelity simulators in education has been beneficial, the cost of such simulations (e.g. high-fidelity simulators, space) are substantial. For this reason, other avenues, such as virtual reality simulation should be considered when appropriate to meet the learning objectives. Second Life (SL), which is an on-line, 3D multi-user virtual environment (MUVE), has been used in health training such as identifying certain heart sounds, assessing patients, and engaging in reflective practice. SL supports interactivity such as exploration, role play, simulations, interactions and experimentation via avatars ${ }^{[19]}$. An avatar is an online manifestation of self in a virtual world designed to enhance interactions in a virtual space ${ }^{[20]}$. Three key benefits have been identified with SL as a learning medium: 1) gives users the ability to complete tasks that would be difficult to achieve in real world (due to cost or location restraints); 2) have continuing and growing social interaction capabilities, serving as a basis for collaborative education; and 3) can adapt and grow as user needs change ${ }^{[21]}$.

Jarmon and colleagues, while examining the nature and process of learning in SL among interdisciplinary graduate students, identified an improvement of interdisciplinary communication awareness and knowledge through their experiences in SL ${ }^{[22]}$. Virtual simulation was compared to human patient simulation (HPS) in a study by Youngblood and colleagues, in which students were trained in either virtual or HPS environments ${ }^{[23]}$. They found that teams trained in virtual reality achieved the same level of skill improvement as those using a HPS. Conradi and colleagues found paramedic students using SL for problem-based learning reported the virtual environment more authentic and collaborative than using paper-based scenarios ${ }^{[24]}$. SL environment allowed for feedback from the 'patients' who increased the benefit of the learning environment. In addition, Andreas and colleagues found that SL augmented face to face learning and supported collaborative student learning ${ }^{[25]}$. 
Through use of simulation, students gain the appropriate skills and make clinical decisions based on their learning while avoiding mishaps in patient safety; thus the learner can participate in a highly realistic clinical immersion session in a safe environment ${ }^{[26]}$. In a virtual reality simulation (as noted in mannequin based simulations), there is no harm done to patients if an incorrect procedure or medication is administered. Virtual reality can offer opportunities to teach larger groups of clinicians in more dynamic environments (e.g. different locations) at a lower cost. Use of virtual reality in education and training is a promising adjunct to current methodologies. Only a few studies have considered the impact on training using virtual reality within the nursing profession. Therefore, the purpose of this study was to determine the impact of virtual reality simulations using SL on knowledge transfer among nursing students.

\section{Methods}

\subsection{Sample and setting}

This study used a quasi-experimental design with a convenience sample of senior level nursing students ( $\mathrm{n}=115)$ in one Midwestern University from September 2009 to April 2010. Student demographic information was not collected; however, the students were primarily recent post-high school completing their final year of a four-year baccalaureate nursing program. Students would have completed six clinical rotations in the acute care setting prior to their senior year.

The students included in the study were enrolled in two courses throughout the study timeframe: Leadership and Management and Transition into Professional Practice. The purpose of the Leadership and Management course is to build on the concepts of team, delegation, motivation, negotiation, problem solving, and leadership from the perspective of the organization rather than that of an individual; whereas the focus of the Transition into Professional Practice course is to assist students to synthesize knowledge and skills required of new graduates including refinement of clinical judgment, problem-solving, priority-setting, time management, and interdisciplinary collaboration and communication. Students are required to take both courses during their senior year (either during the fall or winter term). Each of the courses uses a variety of teaching strategies, including lecture, small group discussion, and case studies. The didactic content (and relevant teaching strategies) were consistent across the two semesters, as the same faculty taught the courses during the study timeframe. For the purpose of this study, nursing students were assigned to the intervention group if they were taking the Leadership and Management course in the fall. The control group took the Transition course in the fall (and Leadership and Management in the winter of 2010). Approval was obtained from the Institutional Review Board prior to study implementation.

\subsection{Control group}

Students in the control group received the traditional didactic content. In addition, the control group participated in the usual role play simulations $(\mathrm{n}=3)$, which is part of all undergraduate courses at the University. Content included in the simulations, which took place in the simulation center at the University, was related to communication and patient safety. Students participated in these simulations in groups of 12-15, with some playing active roles (e.g. staff nurse, charge nurse, nursing assistant, patient/family). The simulations were approximately 30 minutes in length, which included a 15 minute debriefing session. The debriefing session was conducted by a trained facilitator and included an opportunity for students to reflect on the experience. All simulations in the simulation center were conducted and debriefed by the simulation center staff to ensure maximum fidelity of the experience.

\subsection{I ntervention group}

The intervention group also received the traditional didactic content for the two courses. In addition, the students participated in three virtual simulations which took place on a virtual nursing unit in Second Life. These simulations were debriefed by the lead faculty for the simulation center, who is also a member of the research team. The nursing unit consists of three semi-separated rooms, a conference room, and a nursing station ${ }^{[27]}$. Each clinical room has two beds and 
is equipped with wall-mounted blood pressure gauges, bed-side cardiac monitors, medical supply cabinets, a sink, a computer desk, and chairs. The nurse station is equipped with a central desk and computer workspace, crash cart, medication dispensing unit, $\mathrm{x}$-ray view boxes, and wheelchairs. This layout is similar to what nursing students would find in an acute care hospital setting and created a more realistic setting for the simulations to occur as opposed to engaging in role play in a classroom environment.

The intervention group participated in the three simulations during the course of the year-two in the fall and one during the winter term. Each of the simulations were developed using a five step process for simulation development: (1) key concept identification, (2) competency and standard mapping, (3) scenario building, (4) debriefing development, and (5) beta testing and refinement (as needed) of the scenario ${ }^{[28]}$. Using this process for development ensured fidelity and realism of the scenarios. The researchers who created the scenarios for this study have developed over forty-five simulations using the process described, spanning topics related to communication, healthcare professional handoffs, clinical judgment, acute clinical issues (i.e. asthma, heart disease), and patient safety. The focus of the simulations for this study included: (1) communication/conflict management, (2) priority setting, and (3) problem solving related to a patient safety issue. A brief overview of each of the simulation scenarios, as well as the expectations from students, is included in Table 1.

Table 1. Simulation Scenario Overview

\begin{tabular}{|c|c|c|c|}
\hline Simulation Topic (n) & Type of Simulation & Overview & $\begin{array}{l}\text { Course/Date } \\
\text { Implemented }\end{array}$ \\
\hline $\begin{array}{l}\text { Communication/Conflict } \\
\text { Management } \\
(\mathrm{n}=62)\end{array}$ & Virtual Reality & $\begin{array}{l}\text { Theme: Conflict management situation between the registered nurse } \\
\text { and the physician } \\
\text { Expectations: During this exercise students were expected to } \\
\text { adequately manage the physician-nurse conflict situation in a } \\
\text { professional manner }\end{array}$ & $\begin{array}{l}\text { Leadership and } \\
\text { Management } \\
\text { (Oct 2009)* }\end{array}$ \\
\hline $\begin{array}{l}\text { Problem Solving/Patient } \\
\text { Safety } \\
(\mathrm{n}=62)\end{array}$ & Virtual Reality & $\begin{array}{l}\text { Theme: A situation where a patient was given the wrong medication for } \\
\text { which they were allergic to } \\
\text { Expectations: Students cared for the patient appropriately and the } \\
\text { proper channels were followed in coordinating an incident report and } \\
\text { dealing with the situation in an appropriate manner. Feedback to the } \\
\text { nurse who gave the wrong medication was also required. }\end{array}$ & $\begin{array}{l}\text { Leadership and } \\
\text { Management } \\
\text { (November } \\
\text { 2009)* }\end{array}$ \\
\hline $\begin{array}{l}\text { Priority Setting } \\
(\mathrm{n}=62)\end{array}$ & Virtual Reality & $\begin{array}{l}\text { Theme: Nurse was given a set of patients and he/she had to determine } \\
\text { which patient to see first and what tasks were appropriate to delegate to } \\
\text { the patient care technician } \\
\text { Expectations: Adequately manage the care of multiple patients and } \\
\text { identify priorities while maintain a healthy working relationship with } \\
\text { one's co-workers. Students were required to identify and delegate } \\
\text { tasks to the assistive personnel. }\end{array}$ & $\begin{array}{l}\text { Transition into } \\
\text { Professional } \\
\text { Practice } \\
\text { (February } \\
\text { 2010)* }\end{array}$ \\
\hline $\begin{array}{l}\text { Final Simulation } \\
\text { (incorporated all three } \\
\text { topics) } \\
(\mathrm{n}=115)\end{array}$ & $\begin{array}{l}\text { High-fidelity } \\
\text { Simulator }\end{array}$ & $\begin{array}{l}\text { Theme: Nurse must choose which patient to see first and remain } \\
\text { focused on the patient showing signs of respiratory depression. When } \\
\text { the nurse speaks with the physician, she (played by the research } \\
\text { assistant) orders the wrong reversal agent, which the nurse must } \\
\text { identify and then work through communication difficulties with the } \\
\text { physician. } \\
\text { Expectations: Nurse must stay focused on the patient, despite attempts } \\
\text { to bring her off task. The nurse must work through the difficult } \\
\text { communication interaction with the physician. }\end{array}$ & $\begin{array}{l}\text { All students } \\
\text { (April 2010) }\end{array}$ \\
\hline
\end{tabular}

*Only the intervention group participated in the virtual simulations although content related to the topic was received by both groups (intervention and control)

All students in the intervention group were given an overview of SL during the didactic portion of their fall course. In addition, students were given a handout that highlighted basic skills needed to use SL (e.g. account set up, avatar creation, 
communication in SL, movement in SL). Students were encouraged to develop their own avatars and explore the world prior to the simulations, although not a requirement.

Each of the simulations took place on the virtual nursing unit in SL, which was accessed in the campus computer lab. Students in the intervention group participated in the simulations in groups of 12-15 students. Students who played an active role in the scenario (either playing the role of a staff nurse, charge nurse, patient/family, or assistive personnel) logged onto SL and met in the virtual conference room where the facilitator (i.e. a research team member) gave an overview of the scenario, reminders as to how to communicate and move in SL, and any scenario-specific instructions. Students were then given an opportunity to practice for a few minutes moving their avatars and using the chat function before the simulation began.

Students who did not play an active role in the scenario observed the simulation in a separate classroom (SL was projected on a screen). During subsequent simulations, the students who were observers were asked to play active roles, thus the majority of students played an active role in one of the scenarios. A facilitator was present in each area to guide the activity. This included providing note cards (cue cards) in SL, giving the students directions on how to play the role, as well as some scripting for those playing the patient/family role. Following the conclusion of the scenario, all students participated in the debriefing session, which included a discussion of the scenario (e.g. 'What went well?') and ways to improve performance in the future (e.g. 'How might you have done this differently?'). The total time for each simulation was approximately 35 minutes (15-20 minutes for the simulation and an additional 15 minutes for debriefing).

\subsection{Evaluation of knowledge transfer}

At the end of the academic year, all students (intervention and control groups) participated in a mannequin based simulation to evaluate knowledge transfer, defined as the ability of students to take what is learned in the classroom and transfer those skills into practice. Nursing students in both the control and intervention group participated in a final simulation using a high fidelity patient simulator (Laerdal SimMan@). Each nursing student participated in the final simulation individually, playing the role of the staff nurse. The final simulation (see Table 1), which involved a patient with respiratory compromise related to over sedation, incorporated all of the key concepts included in the didactic learning and virtual simulations. Prior to the start of the simulation, students were given instructions as to the purpose of the scenario. The role of the physician was played by one of the simulation center staff to ensure consistency and fidelity. The simulation lasted approximately 15 minutes, with an additional 15 minutes of debriefing. To evaluate each student's performance, students were evaluated on their performance using an adapted version of the Capacity to Rescue Instrument ${ }^{[29]}$.

The original Capacity to Rescue Instrument (CRI) is a 22 item scale used to measure assessments and interventions completed by a participant in a simulation to evaluate overall performance. The instrument was designed to capture key elements (assessments, interventions) that are needed to ensure a good outcome for the patient for a specific simulation scenario. The key elements are based on current evidence-based practices or best practices and are key to the outcome of the scenario as designed. The original instrument underwent psychometric testing including factor analysis during its initial development as part of a study to measure rescue behaviors in nurses in a sepsis scenario designed for use with a high fidelity simulator ${ }^{[29]}$. The original study used a dichotomous scale to indicate whether or not the nurse performed the expected assessment or intervention. The nurse participated in a 20 minute sepsis scenario and the CRI was used to determine his/her overall performance in the scenario. The original scale alpha was 0.69 and the factor analysis identified two factors; recognition (assessments) and appropriate actions (interventions). Correlations between the CRI and the simulation patient outcome were $0.78^{[29]}$.

For the purpose of this study, the modified CRI consisted of 17 items measuring key concepts: communication $(n=9)$, problem solving $(n=4)$, and priority setting $(n=4)$. As with the original CRI, the items were relevant to the scenario used and consisted of key assessment and interventions the student needed to perform to support a good patient outcome. The 
higher score indicates a better overall performance in the scenario. All variables were scored as either being complete (2), partially complete (1), or no action taken (0). For example, the student nurse would receive full credit (2 points) if she communicated that the patient received an additional dosage of Dilaudid. Partial completion was given if the nurse mentioned the patient received an additional dose of pain medication (but did not specify Dilaudid); and no action was marked if the student failed to mention any additional dosage of pain medication.

The CRI items—scored individually — were summed to compute a total performance score. The possible scores can range from 0-34. The CRI survey was completed for each student by a trained observer. Prior to the evaluation of student performance, inter-rater reliability among the observers $(n=2)$ was performed using videos of simulation scenarios $(n=4)$. The observers independently rated each scenario and compared results until $>90 \%$ reliability was achieved.

\subsection{Statistical analysis}

Data were analyzed using the SPSS ${ }^{\circledR}$ (Chicago, IL) version 17.0 for Windows ${ }^{\circledR}$ software. Computations for frequencies, percentages, means, ranges, and standard deviations were completed. To determine the impact of virtual simulations on knowledge transfer (i.e. student performance as rated by the CRI), comparisons of means were made between the control and intervention group using ANOVA. Differences with a $p<.05$ were considered statistically significant.

\section{Results}

A total of 115 senior baccalaureate students at one Midwest University were included in the study: 62 students in the intervention group and 53 students in the control group. An overview of average scores and standard deviations for each of the items contained in the CRI are included in Table 2. Overall performance was measured as a sum total of each of the items on the CRI. Total score for the control group, on average, was 20.09 (SD 4.05); average CRI score for the intervention group was 21.98 (SD 4.29).

Four items addressed the students' ability to prioritize the care needed by the patient. The student nurse chose the correct patient, on average, 1.36 (SD 0.94) for the control group and 1.74 (SD 0.68) for the intervention group, respectively. Despite efforts to distract the nurse by suggesting she take care of another situation on the unit (i.e. another patient vomited and a physician was requesting her assistance), nurses in both the control $(\mathrm{m}=1.96$, SD 0.19) and intervention group $(m=1.94, S D$ 0.25) were likely to stay with the patient. When the physician attempted to leave the room, nursing students in the intervention group were more likely ( $m=1.47$, SD 0.67 ) to let her leave than in the control group ( $m=1.34$, SD 0.78). Students in the control group were more likely to stay focused $(\mathrm{m}=1.62$, SD 0.77$)$ on the patient throughout the simulation than the intervention group ( $\mathrm{m}=1.47$, SD 0.84$)$.

Nine items evaluated the student's ability to communicate effectively during the simulation. When speaking with the physician regarding the patient's condition, students, on average, mentioned the additional dose of a narcotic ( $\mathrm{m}=1.79$ 1.81, SD 0.47-0.50 for control and intervention group, respectively). Students in the intervention group, on average, were more likely to communicate the neurologic change $(\mathrm{m}=1.90$, SD 0.39$)$ than the control group $(\mathrm{m}=1.81$, SD 0.52$)$, as well as the current vital signs (intervention group, $\mathrm{m}=1.61$, SD 0.49 ; control group, $\mathrm{m}=1.38$, SD 0.56). In addition, the intervention group of students were more likely to use the standardized handoff tool SBAR (situation, background, assessment, recommendation) ${ }^{[30]}$, as noted by a mean of 1.21 (SD 0.48) as compared to the control group (m=1.06, SD 0.36). In both the control and intervention group, delegation to an additional nurse did not occur often $(\mathrm{m}=0.30$, SD 0.79 for control group; $\mathrm{m}=0.50$, SD 0.86 for intervention group). In subsequent communication with the physician, average scores on the information communicated included the following: lung sounds (intervention group, $\mathrm{m}=0.16, \mathrm{SD} 0.55$; control group, $m=0.19$, SD 0.59), history of Congestive Heart Failure ( $m=0.29$, SD0.71, $m=0.02$, SD 0.14 for intervention and control group, respectively), identification of Narcan as the right reversal agent (intervention group, m=1.16, SD 1.0; control group, $m=1.25$, SD 0.98). In terms of management of the difficulty in communication with the physician, the 
intervention group, on average, was more likely to escalate the situation to the next level ( $m=0.84$, SD 0.93 ) as compared to the control group ( $\mathrm{m}=0.64$, SD 0.86$)$.

Table 2. Statistics of Performance among the Intervention and Control Group

\begin{tabular}{|c|c|c|c|c|c|}
\hline \multirow{2}{*}{ Variable } & \multicolumn{2}{|c|}{ Intervention Group (n=62) } & \multicolumn{3}{|c|}{ Control Group (n=53) } \\
\hline & Mean & SD & Mean & SD & Sig \\
\hline \multicolumn{6}{|l|}{ Priority Setting } \\
\hline Nurse sees the correct patient & 1.74 & 0.68 & 1.36 & 0.94 & 0.01 \\
\hline Nurse did not leave the patient & 1.94 & 0.25 & 1.96 & 0.19 & 0.52 \\
\hline Nurse stops physician from leaving the room & 1.47 & 0.67 & 1.34 & 0.78 & 0.35 \\
\hline Nurse remains focused on patient & 1.47 & 0.84 & 1.62 & 0.77 & 0.31 \\
\hline \multicolumn{6}{|l|}{ Communication } \\
\hline Nurse communicates additional dose of Dilaudid & 1.81 & 0.47 & 1.79 & 0.50 & 0.88 \\
\hline $\begin{array}{l}\text { Nurse communicates patient’s neurological } \\
\text { status }\end{array}$ & 1.90 & 0.39 & 1.81 & 0.52 & 0.28 \\
\hline Nurse communicates current vital signs & 1.61 & 0.49 & 1.38 & 0.56 & $<0.02$ \\
\hline Nurse communicates using SBAR & 1.21 & 0.48 & 1.06 & 0.36 & 0.06 \\
\hline Nurse delegates tasks to a second nurse & 0.50 & 0.86 & 0.30 & 0.79 & 0.18 \\
\hline Nurse communicates history of $\mathrm{CHF}$ & 0.29 & 0.71 & 0.02 & 0.14 & $<0.01$ \\
\hline Nurse communicates lung sounds & 0.16 & 0.55 & 0.19 & 0.59 & 0.80 \\
\hline $\begin{array}{l}\text { Nurse communicates Narcan is the correct } \\
\text { reversal agent }\end{array}$ & 1.16 & 0.99 & 1.25 & 0.98 & 0.65 \\
\hline $\begin{array}{l}\text { Nurse discusses with the physician the need to } \\
\text { escalate the situation to the next level }\end{array}$ & 0.84 & 0.93 & 0.64 & 0.86 & 0.24 \\
\hline \multicolumn{6}{|l|}{ Problem Solving } \\
\hline Nurse requests assistance & 1.81 & 0.60 & 1.85 & 0.53 & 0.69 \\
\hline Nurse recognizes that a reversal agent is needed & 1.66 & 0.51 & 1.43 & 0.69 & $<0.05$ \\
\hline Nurse requests an order form the physician & 1.77 & 0.61 & 1.64 & 0.68 & 0.27 \\
\hline Nurse asks for assistance from a second nurse & 0.58 & 0.92 & 0.42 & 0.82 & 0.31 \\
\hline Total Score & 21.98 & 4.29 & 20.09 & 4.05 & $<0.02$ \\
\hline
\end{tabular}

To evaluate the student's ability to problem-solve, four items were included in the CRI. Students in both the control and intervention group were equally as likely to request assistance (intervention group, $\mathrm{m}=1.81$, SD 0.60; control group, $\mathrm{m}=1.85$, SD 0.53). Students nurses in the intervention group were more likely to recognize the need for a reversal $(\mathrm{m}=1.66$, SD 0.51 for intervention group; $m=1.43$, SD 0.69 for control group). The students in the intervention group were more likely to request an order from the physician (= 1.66, SD 0.51$)$ as compared to the control group ( $\mathrm{m}=1.43$, SD 0.69$)$. In terms of asking for assistance from another nurse, both groups were unlikely to ask for assistance from another nurse (intervention group, $\mathrm{m}=0.58$, SD 0.92; control group, $\mathrm{m}=0.42$, SD 0.82 ).

\section{Comparison of overall performance between the control and intervention group}

ANOVAs were computed to determine significant variation among overall performance among the intervention and control group (see Table 2). Students in the intervention group were more likely to perform better in the final individual simulation than students in the control group $[F(1,113)=5.84, p<0.02]$. In review of the individual items evaluated on the CRI, four items were found to be significantly different between the two groups. Students in the intervention group were more likely to prioritize correctly by choosing the right patient to see first $[\mathrm{F}(1,113)=6.41, p=0.01]$. Students in the intervention group were also more likely to communicate vital sign findings when communicating with the physician $[\mathrm{F}(113)=5.75, p<0.02]$ and the patient's history of $\mathrm{CHF}[\mathrm{F}(1,113)=7.49, p<0.01]$. Students in the intervention group were also significantly more likely to recognize the need for a reversal agent than those in the control group $[F(1,113)=4.08$, 
$p<0.05]$. In addition, use of SBAR for communicating patient information was approaching significance, with the intervention group more likely using the standardized handoff tool than the control group $[\mathrm{F}(1,113)=3.59, p=0.06]$.

\section{Discussion}

The primary purpose of this study was to identify whether virtual simulation, in addition to the traditional teaching methods, enhanced the knowledge transfer of content presented to senior nursing students. In order to effectively comprehend many of the topics taught in the classroom, students must have the opportunity to deliberately 'practice' these skills in the clinical setting. For the intervention group, deliberate 'practice' occurred through participation in three content-focused virtual simulations (e.g. priority setting, communication/conflict management, problem solving). Findings indentified a significant difference between the two groups on overall performance. Specifically, those in the intervention group performed better in the final simulation, thus providing evidence that they were able to transfer didactic content into the clinical setting better than those that did not participate in the virtual simulations. This is in line with much of the literature on simulation ${ }^{[15]}$. Also, this helps in understanding the role virtual simulations may play in future nursing education. Although the control group received some opportunity to practice skills via traditional simulation, students participating in virtual simulations performed better. This may be due to the 'realism' of the virtual environment and the ability of students to engage fully in the 'practice' session. In virtual reality, their true identify is somewhat anonymous ${ }^{\text {[31]; }}$ therefore, students may feel more confident in trying new skills (without fear of repercussion or ridicule from peers).

Although the difference in total score between the two groups was relatively small (approximately 2 points), there is clinical significance when considering the context of patient care. A two point difference in this study equates to 'no action' to complete a needed intervention. For example, if the nurse 'did not stay focused on the patient' and instead left the room to care for another patient, the identification and subsequent treatment of respiratory depression would have been delayed, which could have resulted in a very negative outcome for the patient. All nursing interventions contribute to patient safety and effective patient care.

Students in the intervention group were also significantly more likely to identify the correct patient to be seen at the start of the final simulation (i.e. given three choices, the student successfully identified the most critical patient). In addition, the intervention group was significantly better at communicating key patient characteristics to the physician in the final simulation. Specifically, those in the intervention group were significantly better at communicating current vital signs and the patient's history of CHF. In addition, this information was more likely to be communicated using the standardized handoff strategy of SBAR ${ }^{[30]}$. The ability of the intervention group in communicating more effectively may be related to the fact they were able to practice their skills in a very deliberate manner in the virtual simulations. Although communication was required in the simulations for the control group, it was more generalized and did not require a specific standardized structure. This finding is in line with Ericsson's framework which reinforces the need for deliberate practice of key activities (e.g. standardized handoff) for competency to occur ${ }^{[4]}$.

\section{Limitations}

There are limitations of the study that are noteworthy. The sampling method utilized was convenience sampling, thus limiting generalizeability beyond the study population. Due to the large number of students who had to be evaluated on an individual basis, the students were evaluated over a three-week period, thus opportunities for sharing some aspect of the final simulation existed. This limitation was identified and during the debriefing sessions the researchers addressed this issue. Students that had prior knowledge of the scenario were identified and their data was not used in the analysis $(\mathrm{n}=8)$. One final limitation includes the inability to determine if the deliberate practice through the use of simulation transfers to the real world environment. This has been done through in-situ simulations where simulation is physically integrated into the clinical environment. Further research is needed to observe actual student performance in the clinical environment. 


\section{Conclusion}

Nursing education throughout history has changed dramatically with the rise of technological advances, such as high-fidelity mannequins and virtual environments. Research has shown that for mastery of any skill or behavior, deliberate practice is required ${ }^{[4]}$. In addition, recommendations from the Carnegie Report include integrating teaching methods that bridge theory learned in the classroom to actual care of patients in the clinical environment. One of the teaching strategies recommended to bridge this gap included simulation ${ }^{[32]}$.

Simulation provides a mechanism for 'deliberate practice' in a safe, learning environment. Findings of this study revealed the role virtual simulations can play in providing an opportunity for deliberate practice, and subsequent transfer of knowledge learned in the classroom into the clinical setting. Efforts for providing more opportunities for deliberate practice of critical skills (e.g. communication, conflict management, priority setting) must be provided. This can include low technique simulations in the classroom setting, such as with case studies and role-play activities.

The addition of virtual simulations in this study resulted in improved student performance. Use of a virtual environment may provide greater access to practice opportunities at a much lower cost than high fidelity simulators. The virtual environment can provide opportunities for practice of non-technical skills such as clinical judgment, teamwork, communication, and leadership skills. This methodology provides opportunities for practice anywhere internet access is available. In practice areas where it is challenging to get staff away from the bedside or it is difficult to get nurses and physicians together, virtual simulations may provide a viable alternative.

\section{References}

[1] Benner, P., Sutphen, M., Leonard, V., Day, L. Educating nurses: a call for radical transformation. Jossey-Bass. 2009 ; 1-249.

[2] Page, A. (Ed.). Keeping patients safe: Transforming the work environment of nurses. Washington, DC: National Academies Press. 2004.

[3] Prawat, R.S. Promoting access to knowledge, strategy, and disposition in students: a research synthesis. Review of Educational Research. 1989; 59(1): 1-41.

[4] Ericsson, K. A. Deliberate practice and the acquisition and maintenance of expert performance in medicine and related domains. Academic Medicine: Journal of the Association of American Medical Colleges. 2004; 79(10 Suppl): S70-81.

[5] Carnegie Foundation for the Advancement of Teaching. Educating nurses: A call for radical transformation [Internet]. Available from: http://www.carnegiefoundation.org/newsroom/press-releases/educating-nurses-call-radical-transformation. Retrieved February 8, 2010.

[6] Bearnson, C. S., Wiker, K. M. Human patient simulators: a new face in baccalaureate nursing education at Brigham Young University. Journal of Nursing Education. 2005; 44(9): 421-425. PMid:16220650

[7] Nehring, W.M., Lashley, W.R. Current uses and opinions regarding human patient simulators in nursing education: an international survey. Nursing Education Perspectives. 2004; 25(5): 244-248. PMid:15508564

[8] Morgan, P. J., Cleave-Hogg, D., Mcllroy, J., Devitt, J.H. Simulation technology: a comparison of experiential and visual learning for undergraduate medical students. Anesthesiology. 2002; 96: 10-16. PMid:11752995

http://dx.doi.org/10.1097/00000542-200201000-00008

[9] Ericksen, J. R., Grantcharov, T. Objective assessment of laparoscopic skills using a virtual reality stimulator. Surgical Endoscopy and Other Interventional Techniques. 2005; 19(9): 1216-1219. PMid:16132335 http://dx.doi.org/10.1007/s00464-004-2154-y

[10] Van Sickle, K. R., McClusky, D. A., Gallagher, A. G., Smith, C. D. Construct validation of the ProMIS simulator using a novel laparoscopic suturing task. Surgical Endoscopy and Other Interventional Techniques. 2005; 19(9): 1227-1231. PMid:16025195 http://dx.doi.org/10.1007/s00464-004-8274-6

[11] Maithel, S., Sierra, R., Korndorffer, J., Neumann, P., Dawson, S., Callery, M., Jones, D., Scott, D. Construct and face validity of MIST-VR, endotower, and CELTS - are we ready for skills assessment using simulators? Surgical Endoscopy and Other Interventional Techniques. 2006; 20(1): 104-112. PMid:16333535 http://dx.doi.org/10.1007/s00464-005-0054-4

[12] Rosenthal, M. E., Adachi, M., Ribaudo, V., Mueck, J. T., Schneider, R. F., Mayo, P. H. Achieving housestaff competence in emergency airway management using scenario based simulation training - comparison of attending vs housestaff trainers. Chest. 2006; 129(6): 1453-1458. PMid:16778261 http://dx.doi.org/10.1378/chest.129.6.1453 
[13] Harder, N.B. Use of simulation in teaching and learning in health sciences: a systematic review. Journal of Nursing Education. 2010; 49(1): 23-28. PMid:19731886 http://dx.doi.org/10.3928/01484834-20090828-08

[14] Owen, H., Mugford, B., Follows, V., Plummer, J.L. Comparison of three simulation-based training methods for management of medical emergencies. Resuscitation. 2006; 71: 204-211. PMid:16987587 http://dx.doi.org/10.1016/j.resuscitation.2006.04.007

[15] Wayne, D. B., Didwania, A., Feinglass, J., Fudala, M. J., Barsuk, J. H., McGaghie, W. C. Simulation-based education improves quality of care during cardiac arrest team responses at an academic teaching hospital: A case-control study. Chest. 2008; 133(1): 56-61. PMid:17573509 http://dx.doi.org/10.1378/chest.07-0131

[16] Aebersold, M. Using simulation to improve the use of evidence-based practice guidelines. Western Journal of Nursing Research. 2010; 33(3): 296-305. PMid:20876552 http://dx.doi.org/10.1177/0193945910379791

[17] Scherer, Y.K., Bruce, S.A., Runkawatt, V. A comparison of clinical simulation and case study presentation on nurse practitioner students' knowledge and confidence in managing cardiac event International Journal of Nursing Education Scholarship. $2007 ; 4$.

[18] Morgan, P. J., \& Cleave-Hogg, D. Comparison between medical students' experience, confidence and competence. Medical Education, 2002, 36(6): 534-539. PMid:12047667 http://dx.doi.org/10.1046/j.1365-2923.2002.01228.x

[19] Clarke, J. Dede, C. Ketelhut, D.J. Nelson, B. A design-based research strategy to promote scalability for educational innovations. Educational Technology. 2006, 46(3): 27-36.

[20] Peterson, M. Learning interaction in an avatar-based virtual environment: a preliminary study. PacCALL Journal. $2005 ; 1: 29-40$.

[21] Johnson, A., Ramos-Alarilla, J., Harilal, K., Case, D., Dillon, E. HPS more effective than CD-ROM for improving cognition and performance. Clinical Simulation in Nursing, published on-line. August 8, 2011.

[22] Jarmon, L. Traphagan, T., Mayrath, M., Trivedi, A. Virtual world teaching, experiential learning and assessment: an interdisciplinary communication course in Second Life. Computers \& Education. 2009; 53(1): 169-182. http://dx.doi.org/10.1016/j.compedu.2009.01.010

[23] Youngblood, P., Harter, P.M., Srivastava, S., Moffett, S. Heinrichs, W.L., Dev, P. Design, development, and evaluation of an online virtual emergency department for training trauma teams. Simulation in Healthcare. 2008; 3: 146-153. PMid:19088658 http://dx.doi.org/10.1097/SIH.0b013e31817bedf7

[24] Conradi, E., Kavia, S., Burden, D., Rice, A., Woodham, L., Beaumont, C., Savin-Baden, M., et al. Virtual patients in a virtual world: training paramedic students for practice. Medical Teacher. 2009; 31: 713-720. PMid:19811207 http://dx.doi.org/10.1080/01421590903134160

[25] Andreas, K., Tsiatsos, T., Terzidou, T., Pomportsis, A. Fostering collaborative learning in Second Life: metaphors and affordances. Computers \& Education. 2010; 55: 603-615. http://dx.doi.org/10.1016/j.compedu.2010.02.021

[26] Yaeger, K, Halamek, L, Coyle, M, Murphy, A, Anderson, J, Boyle, K, et al. High-fidelity simulation-based training in neonatal nursing. Advances in Neonatal Care. 2004; 4(6): 326-331. PMid:15609254 http://dx.doi.org/10.1016/j.adnc.2004.09.009

[27] Aebersold, M., Tschannen, D., Stephens, M., Anderson, P., Lei, X. Second life_: A new strategy in educating nursing students. Clinical Simulation in Nursing, in press.

[28] Tschannen, D., Aebersold, M. "Second Life: Innovative simulation development-making it REAL! Paper presentation at the International Academic Conference of Meaningful Play, 2010, Lansing, MI.

[29] Aebersold, M. Capacity to Rescue: Nurse Behaviors that Rescue Patients. http://hdl.handle.net/2027.42/60718. Unpublished Dissertation, University of Michigan, 2008.

[30] Haig, K., Sutton, S., \& Whittington, J. SBAR: a shared mental model for improving communication between clinicians. Journal on Quality and Patient Safety. 2006; 32(3): 167-175.

[31] Pfeil, U., Ang, C. S., Zaphiris, P. Issues and challenges of teaching and learning in 3D virtual worlds: real life case studies. Educational Media International. 2009; 46(3): 223-238. http://dx.doi.org/10.1080/09523980903135368

[32] Benner, P., Sutphen, M., Leonard, V., Day, L. Educating Nurses: A Call for Radical Transformation. Carnegie Foundation. 2009. 